Check for updates

Cite this: Mater. Adv., 2021, 2, 5650

Received 27th April 2021 Accepted 13th July 2021

DOI: $10.1039 / \mathrm{d} 1 \mathrm{ma00381j}$

rsc.li/materials-advances

\title{
Sustainable oxygen evolution catalysis - electrochemical generation of mössbauerite via corrosion engineering of steel + t
}

\author{
Sebastian Weiß, ${ }^{\mathrm{ab}}$ A. V. Radha, ${ }^{\mathrm{b}}$ Michael Ertl, ${ }^{\mathrm{b}}$ Catherine McCammon (D) $^{\mathrm{c}}$ and \\ Josef Breu (iD *ab
}

\begin{abstract}
A versatile electrochemical corrosion process was used to generate green rust (GR) on a steel substrate and to transform it into the trivalent iron-only oxygen evolution catalyst mössbauerite (GR*) upon a subsequent oxidation process. Besides being scalable, cheap, and time-efficient, the demonstrated procedure is based on earth-abundant and non-hazardous materials only. Oxidation of mixed-valence $\mathrm{Fe}^{2+} / \mathrm{Fe}^{3+} \mathrm{GR}$ to $\mathrm{GR}^{*}$ was achieved by chemical and electrochemical processes. The latter induces less grafting of interlayer $\mathrm{CO}_{3}{ }^{2-}$, leading to less contraction of the interlayer space and a reduction in the observable stacking disorder. The direct electrodeposition of the catalyst on a conductive substrate enabled the first systematic study of the impact of grafting on the performance of $\mathrm{GR}^{\star}$ in the oxygen evolution reaction (OER). The materials subjected to chemical $\left(\mathrm{GR}^{*}{ }_{\mathrm{ChO}}\right)$ and electrochemical oxidation $\left(G R^{\star}{ }_{\text {EIOx }}\right.$ ) allowed obtaining a current density of $100 \mathrm{~mA} \mathrm{~cm}{ }^{-2}$ at $1.82 \mathrm{~V}$ and $1.84 \mathrm{~V}$, respectively, thus improving the electrocatalytic capabilities and outperforming the bare steel substrate operated in $1 \mathrm{M}$ $\mathrm{KOH}$ solutions.
\end{abstract}

\section{Introduction}

Resolving energy and environmental issues has been receiving enormous attention. It can be regarded as the critical challenge of the 21st century. ${ }^{1,2}$ Most of the proposed strategies focus on renewable energies to curb $\mathrm{CO}_{2}$ emissions by gradually turning away from conventional fossil energy sources. Due to the intermittent nature of these energy sources, suitable storage methods are imperative to provide a continuous energy supply for grid management. ${ }^{3}$ For instance, energy can be stored in the form of chemical bonds, e.g., hydrogen. However, the bottleneck for establishing a hydrogen-based storage cycle is linked to the oxidative half-reaction, called the oxygen evolution reaction (OER). ${ }^{4}$ Moreover, for green energy production, environmentally friendly, earth-abundant, non-hazardous, and affordable elements allowing for technically benign processing are preferred. Such materials with

\footnotetext{
${ }^{a}$ Bavarian Center for Battery Technology (BayBatt), University of Bayreuth, Universitätsstr. 30, 95447 Bayreuth, Germany

${ }^{b}$ Department of Chemistry, University of Bayreuth, Universitätsstr. 30, 95447 Bayreuth, Germany. E-mail: josef.breu@uni-bayreuth.de ${ }^{c}$ Bayerisches Geoinstitut, University of Bayreuth, Universitätsstr. 30, 95447 Bayreuth, Germany

$\dagger$ Dedicated to Prof. Dr Wolfgang Schuhmann on the occasion of his 65th birthday.

\# Electronic supplementary information (ESI) available: CV, SEM, Mössbauer spectroscopy, CP, and post-catalysis SEM/XRD. See DOI: 10.1039/d1ma00381j
}

efficient and durable electrocatalytic properties will play a pivotal role in future developments in this field. ${ }^{5}$

Ideally, cheap and scalable anodes for the OER are highly sought-after since noble metal oxides are considered unsuitable due to dissolution, high production price, and catalyst material maintenance. ${ }^{6}$ Being affordable and easy to manufacture, iron-based electrodes represent a viable option. Unfortunately, under OER operating conditions, the Pourbaix diagram of iron implies the dissolution of the electrode through the formation of ferrate $\left(\mathrm{FeO}_{4}{ }^{2-}\right)$ anions. ${ }^{7}$ The dissolved ferrate is not stable in aqueous environments at $\mathrm{pH} 14$ and will thus oxidize water to produce oxygen. ${ }^{8}$ Concomitantly, with the reduction of the ferrate, undesirable corrosion products of iron are formed on the steel surface. ${ }^{9}$ The formation of this passivation layer may impede further corrosion but may also impair the performance of the electrode due to the low conductivity and/or lacking activity of the formed products. ${ }^{10}$

Using stainless steel, this uncontrolled rusting of the electrode can be mitigated. Among the other transition metal additives, stainless steels typically contain at least $12 \mathrm{wt} \%$ of chromium to reduce susceptibility to corrosion. ${ }^{11}$ Under ambient conditions, a thin chromium oxide layer passivates the surface. This, however, has been reported to contribute little or even reduce the OER activity of the stainless steel. ${ }^{12,13}$ The Pourbaix diagram of $\mathrm{Cr}$, moreover, indicates that the formation of $\mathrm{CrO}_{4}{ }^{2-}$ is thermodynamically favored under OER operating 
conditions. ${ }^{14}$ Indeed, previous studies have shown Cr leaching into the electrolyte in the long term. ${ }^{13,15,16}$ The dissolution of chromium under sufficiently high anodic potentials has even been utilized to obtain thin $\mathrm{Ni}-\mathrm{Fe}$ oxide layers representing a robust OER catalyst. ${ }^{17}$ However, $\mathrm{Cr}(\mathrm{VI})$ is known to be carcinogenic and must not be released into the environment but rather needs to be completely removed upon exchanging the electrolyte. ${ }^{18,19}$ Nevertheless, these and other ${ }^{13,20,21}$ studies clearly have proven the efficiency of oxidic layers on Fe-based substrates for OER catalysis. The steel types applied, however, often contain environmentally unfriendly or even toxic elements like $\mathrm{Co}, \mathrm{Cr}$, and $\mathrm{Ni}$ while processing often is timeconsuming and requires harsh conditions.

Layered double hydroxides (LDHs) are regarded as one of the most promising classes of OER catalysts ${ }^{22}$ owing to the fact that they exhibit compositional flexibility and allow for tuning of the morphology. When optimizing the electrocatalytic properties, these features allow for the optimization of electronic structures while providing high specific surface area at the same time. ${ }^{22}$ Generally, the composition of carbonateLDHs can be described as $\mathrm{M}_{6-x}{ }^{2+} \mathrm{M}_{x}{ }^{3+}(\mathrm{OH})_{12}\left(\mathrm{CO}_{3}\right)_{x / 2} \cdot n \mathrm{H}_{2} \mathrm{O}$ with $0 \leq x \leq 2$. Previously, we have shown that the trivalent Fe-only (oxy)hydroxide mössbauerite $\left(\mathrm{GR}^{*} ; \mathrm{Fe}^{\mathrm{III}}{ }_{6}(\mathrm{O})_{4}(\mathrm{OH})_{8}\left(\mathrm{CO}_{3}\right) \cdot 3 \mathrm{H}_{2} \mathrm{O}\right)$ is an n-type semiconductor and exhibits electrocatalytic activity promoting the OER. ${ }^{23}$ The catalyst is obtained by the quick oxidation of the mixed-valence mineral green rust (GR; $\mathrm{Fe}^{\mathrm{II}}{ }_{4}$ $\left.\mathrm{Fe}^{\mathrm{III}}{ }_{2}(\mathrm{OH})_{12}\left(\mathrm{CO}_{3}\right) \cdot 3 \mathrm{H}_{2} \mathrm{O}\right)$. In terms of structure, GR consists of positively charged brucite-like layers containing di-/trivalent cations, interlayered anions, and structural water. ${ }^{24}$ Under ambient oxygen fugacity, GR is susceptible to oxidation and can form various ferric oxyhydroxides like goethite, feroxyhyte, and lepidocrocite. ${ }^{25,26}$ However, fast chemical oxidation using $\mathrm{H}_{2} \mathrm{O}_{2}$ leads to the formation of $\mathrm{GR}^{*}{ }^{23}$

Herein, we report the direct electrochemical coating of environmentally friendly, all-iron GR on a steel surface and its subsequent conversion into the efficient OER catalyst $\mathrm{GR}^{*}$ (Fig. 1). Anodes are fabricated from inexpensive steel via an electrochemical corrosion process producing GR, which is subsequently transformed into the active OER catalyst $\mathrm{GR}^{*}$. Two alternative routes for the conversion were explored, which influence the grafting behavior of the interlayer carbonate:

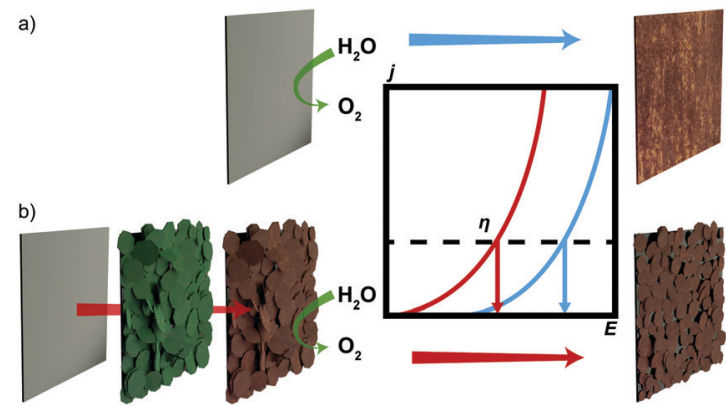

Fig. 1 Schematic comparison of the current-voltage curve for the OER of an unmodified bare steel substrate (a) and the same substrate coated with the all-iron electrocatalyst GR* via a corrosion engineering process (b). either via chemical oxidation $\left(\mathrm{GR}^{*}{ }_{\mathrm{ChOx}}\right)$ using $\mathrm{H}_{2} \mathrm{O}_{2}$ or via an electro-oxidation process $\left(\mathrm{GR}^{*}{ }_{\text {ElOx }}\right)$. The variation in the structure and the electrochemical performance of the oxidized products obtained by these two methods are compared.

\section{Experimental}

\section{Materials}

All solutions used to synthesize the catalysts were prepared with Ar-saturated Milli-Q water (18.2 $\mathrm{M} \Omega \mathrm{cm})$. Hydrogen peroxide solution (30\%) and ethanol absolute were supplied by VWR Chemicals. Potassium hydroxide was ordered from Bernd Kraft $\mathrm{GmbH}$ and sodium bicarbonate from Grüssing $\mathrm{GmbH}$. Substrates were prepared using custom-cut steel plates (DC 01 DIN EN 10130, Maschinenbau Feld $\mathrm{GmbH}$ ). The nail varnish (shine last \& go! gel nail polish; absolute pure) was bought from Cosnova GmbH.

\section{Electrodeposition of GR and its conversion into GR*}

Steel plates were cut to square-sized pieces of $1.4 \mathrm{~cm}$ length and any potentially pre-formed corrosion products were removed using grade $\mathrm{P} 400$ grinding paper and were further polished with $0.3 \mu \mathrm{m} \mathrm{Al}{ }_{2} \mathrm{O}_{3}$ powder. Then, they were cleaned by ultrasonication with ethanol for 5 minutes. Finally, each electrode was rinsed with water and ethanol to remove the remaining loose metal particles and organic contaminants. Electrical contact was provided by using a PTFE-insulated Ag-wire and conductive silver adhesive. UV-curing glue was used to seal any exposed silver. According to a previously published procedure, ${ }^{27}$ the plates were placed in a $0.4 \mathrm{M} \mathrm{NaHCO}_{3}$ solution with the $\mathrm{pH}$ adjusted to 9.6 by the dropwise addition of $10 \mathrm{M}$ $\mathrm{NaOH}$ solution. Electrodeposition and electro-oxidation were conducted using a $\mathrm{CH}$-Instruments potentiostat $710 \mathrm{E}$ in a 3-electrode setup. A Fisher-type double net $\mathrm{Pt} / \mathrm{Ir}$ electrode $(\varnothing 3 \mathrm{~cm})$ and a HydroFlex ${ }^{\circledR}$ hydrogen reference electrode from Gaskatel were used as the counter electrode and reference electrode, respectively. The plates were cycled from 0 to $0.2 \mathrm{~V}$ $v s$. RHE for 90 cycles with a scan speed of $10 \mathrm{mV} \mathrm{s}^{-1}$. After completion, a greenish deposit was visible on the surface of the substrate. As a control experiment, the substrate was immersed in the given solution without any applied potential. Here, no formation of a deposit was observed after 12 weeks.

For the complete oxidation of the mixed-valence GR to GR*, two different methods were employed. For chemical oxidation, the sample was immersed in $40 \mathrm{~mL}$ of a $25 \mathrm{mM}$ aqueous solution of $\mathrm{H}_{2} \mathrm{O}_{2}$. Electrochemical oxidation was achieved by simply increasing the voltage from 1.10 to $1.47 \mathrm{~V} v s$. RHE (typically 5-10 cycles) and subsequently to the electrodeposition of GR. Scanning experiments were performed until no notable current was detectable. Both procedures yielded orange-brown deposits on the steel substrate plates and were then applied as anodes.

\section{Structural characterization of the materials}

To allow for quick measurements to minimize oxidation, powder X-ray diffraction (PXRD) traces for GR were collected 
using a Bragg-Brentano-type diffractometer (Empyrean) with a Ni-filtered $\mathrm{Cu} \mathrm{K}_{\alpha}$ radiation source $(\lambda=1.540598 \AA$ ) equipped with a PIXcel detector. To further reduce fluorescence, PXRD patterns of air-stable GR*-samples were collected using a STOE STADI-P diffractometer with a $\mathrm{Ag} \mathrm{K}_{\alpha 1}$ radiation source $(\lambda=0.5594075 \AA)$ in transmission geometry equipped with four MYTHEN2 R $1 \mathrm{~K}$ detectors. Data collection was performed in the static mode for one hour, with samples loaded in $0.5 \mathrm{~mm}$ glass capillaries. However, to assist comparability, the diffraction traces acquired with $\mathrm{Ag} \mathrm{K}_{\alpha 1}$ radiation (Fig. 2b) were recalculated assuming $\mathrm{Cu} \mathrm{K}_{\alpha}$ radiation. The infrared spectra of the powder samples were recorded using a JASCO FT-IR 6100 spectrometer (400-4000 $\mathrm{cm}^{-1}$ range, $1 \mathrm{~cm}^{-1}$ resolution). Transmission electron microscopy (TEM) images were obtained using a Zeiss/LEO EM922 Omega transmission electron microscope. Scanning electron microscopy (SEM) images were acquired using a Zeiss/LEO 1530 system. For Mössbauer spectroscopy, a small amount of the powder sample was mixed with transparent nail varnish and spread over a region of $1 \mathrm{~mm}$ diameter on a plastic foil. The dimensionless effective sample thickness was estimated to be $12\left(\sim 30 \mathrm{mg} \mathrm{Fe} \mathrm{cm}^{-2}\right.$ ), which is close to the optimum thickness for this composition. $^{28}$ The Mössbauer spectra were recorded at room temperature $(293 \mathrm{~K})$ in the transmission mode using a constant acceleration Mössbauer spectrometer with a nominal $370 \mathrm{MBq}{ }^{57} \mathrm{Co}$ high specific activity source in a $12-\mu \mathrm{m}$-thick $\mathrm{Rh}$ matrix. ${ }^{29,30}$ The velocity scale was calibrated relative to a $25-\mu \mathrm{m}$-thick $\alpha$-Fe foil using the positions certified for the (former) National Bureau of Standards, standard reference material no. 1541; line widths of $0.36 \mathrm{~mm} \mathrm{~s}^{-1}$ for the outer lines of $\alpha$-Fe were obtained at room temperature. The spectrum was collected for one day. The Mössbauer spectra were fitted with MossA software ${ }^{31}$ using the full transmission integral. Data were fitted into doublets with pseudo-Voigt lineshape and conventional constraints (doublet components constrained to have equal widths and areas).

\section{Electrochemical characterization}

Electrochemical characterization was performed using an Autolab potentiostat/galvanostat PGSTAT204. Counter and reference electrodes were the same as those used for the preparation of the material. If not noted otherwise, all electrocatalytic performance
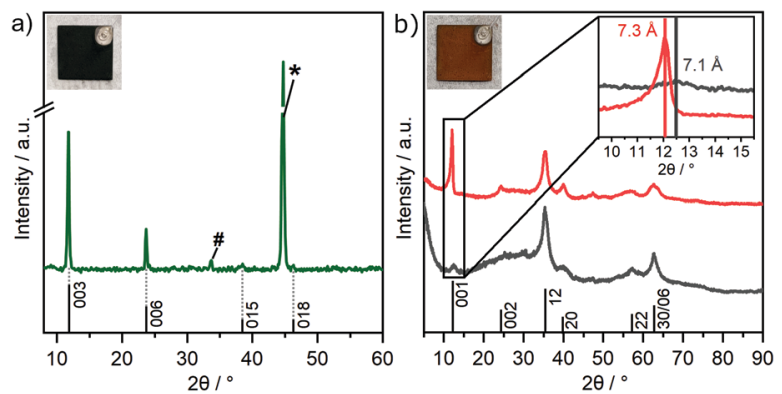

Fig. 2 PXRD patterns of (a) GR on a steel substrate as obtained through an electrochemical corrosion engineering process (*: substrate, \#: partially oxidized product formed during measurements) and (b) scraped off GR* powder as obtained through electro-oxidation (GR* ElOx; red) and chemical oxidation (GR* ChOx; gray) of GR. Photographs of GR and $\mathrm{GR}^{\star}{ }_{\text {ElOx }}$ are shown in the insets. measurements were performed in $\mathrm{O}_{2}$ saturated $1 \mathrm{M} \mathrm{KOH}$ solutions. The electrolyte for all measurements was purified using the cation-exchange resin Chelex ${ }^{\circledR} 100$ (Bio-Rad Laboratories) following the procedure recommended by the producer. ${ }^{32}$ For electrochemical measurements, the exposed surface area was reduced to $1 \mathrm{~cm}^{2}$ by sealing the rest of the plate with hot melt adhesives. The obtained potentials were corrected by $85 \%$ of the uncompensated resistance $(i R)$ determined via current interrupt. Polarization curves were acquired by performing linear sweep voltammetry (LSV) in the range of $1.0-2.5 \mathrm{~V}$ with $5 \mathrm{mV} \mathrm{s}^{-1}$. The overpotential $(\eta)$ is given as the voltage potential difference of $1.23 \mathrm{~V}$. Stability measurements were performed galvanostatically by applying a current of $10 \mathrm{~mA}$, corresponding to a current density of $10 \mathrm{~mA} \mathrm{~cm}{ }^{-2}$, for $24 \mathrm{~h}$. Galvanostatic stability experiments were carried out without $i R$ compensation.

The determination of the electrochemically active surface area (ECSA) was performed by cyclic voltammetry (CV) measurements in an Ar-saturated $1 \mathrm{M} \mathrm{KOH}$ at various scan rates $(10,20$, $40, \ldots, 100 \mathrm{mV} \mathrm{s}^{-1}$ ) in the potential window between $0.210 \mathrm{~V}$ and $0.310 \mathrm{~V}$ vs. RHE where there was no faradaic current response. The double-layer capacitance $\left(C_{\mathrm{dl}}\right)$ was estimated by plotting $\Delta j=j_{\mathrm{a}}-j_{\mathrm{c}}$ at $0.260 \mathrm{~V}$ as a function of the scan rate $\nu$ (eqn (1)). ${ }^{33}$

$$
C_{\mathrm{dl}}=0.5 \cdot(\mathrm{d}(\Delta j) / \mathrm{d} \nu)
$$

The ECSA was calculated by dividing $C_{\mathrm{dl}}$ by the specific capacitance $C_{\mathrm{s}}$ of a flat surface. A value of $C_{\mathrm{S}}=0.04 \mathrm{mF} \mathrm{cm} \mathrm{cm}^{-2}$ was reported as an average value for different metal electrodes in an alkaline environment. ${ }^{34}$

\section{Results and discussion}

Various strategies have been employed to synthesize GR. These include $\mathrm{Fe}^{\mathrm{II}} / \mathrm{Fe}^{\mathrm{III}}$ co-precipitation, ${ }^{23}$ oxidation of ferrous hydroxide, ${ }^{35}$ bacterial reduction of ferric compounds, ${ }^{36}$ and electrosynthesis. ${ }^{37}$ Formation of carbonate interlayered GR has been followed by Génin et al. by tracking the $E_{\mathrm{h}}$ during the reaction. ${ }^{38}$ They further constructed the corresponding Pourbaix diagram, which identifies the stability field of GR with variation in $\mathrm{pH}$ and $E_{\mathrm{h}} \cdot{ }^{38}$ Based on previous investigations, a $\mathrm{pH}$ of 9.6 was considered most suitable to enable a successful deposition. ${ }^{27}$ For this $\mathrm{pH}$, the $E_{\mathrm{h}}$ range of GR can be identified to be located between $0 \mathrm{~V}$ and $0.15 \mathrm{~V}$. For cyclic voltammetry, the window was chosen from $0 \mathrm{~V}$ to $0.2 \mathrm{~V}$ to account for possible overpotentials. After cycling, a greenish deposit was formed on the steel electrode. The intensity of the wave peak recorded during deposition increased steadily, indicating the thickening of the deposited material layer with time (Fig. S1, ESI $\$$ ). The obtained product was characterized utilizing XRD directly on the steel substrate to minimize unintended oxidation by air (Fig. 2a).

The diffraction pattern of GR is in accordance with previous reports on the material (PDF \#00-046-0098). ${ }^{23,39,40}$ The $d$-spacing of $7.5 \AA$ for the first reflection is characteristic for GR containing carbonate ions in the interlayer space and is usually 
assigned as the 003 plane of the $3 R_{1}$ polymorph. ${ }^{23,40}$ The coefficient of variation of the average of the basal spacing as calculated from individual $00 \mathrm{l}$ reflections was found to be small for GR $(0.12 \%)$.

This indicates little variance in the stacking distance of individual interlayers. ${ }^{39}$ As previously found, the remaining, weak in-plane reflections observed are in line with the $3 R_{1}$ polymorph. ${ }^{23,40}$ A prominent reflection at $44.7^{\circ}$ is caused by the underlying substrate and can be assigned to $\alpha-\mathrm{Fe}(110)$ (PDF \#00-006-0696).

Because of the oxygen sensitivity of $\mathrm{GR}^{25}$ a controlled oxidation process is necessary to obtain phase pure $\mathrm{GR}^{*} .^{23}$ Previously, we have shown that this can be achieved by subjecting GR to a $\mathrm{H}_{2} \mathrm{O}_{2}$ treatment as it allows rapid oxidation. Applying this chemical oxidation $\left(\mathrm{GR}^{*}{ }_{\mathrm{ChOx}}\right)$ to the GR deposited on the steel electrode led to an immediate color change from green to orange-brown. Alternatively, the previously deposited GR on the steel substrate was subjected to electrochemical oxidation $\left(\mathrm{GR}^{*}{ }_{\text {ElOx }}\right)$ via cyclic voltammetry in the range of 1.10-1.47 V vs. RHE. A similar color change to orange-brown was observed. A suitable potential range to facilitate the oxidation was identified using cyclic voltammetry over a broad range from 0.60 to $1.57 \mathrm{~V}$ (Fig. S2, ESI $\$$ ). Because both GR* samples are air-stable, the obtained products were scraped off the plate before being characterized using XRD (Fig. 2b).

The powder XRD patterns of both $\mathrm{GR}^{*}$ samples exhibit very few asymmetric and rather broad reflections. The featureless diffraction pattern is typical for $\mathrm{GR}^{*} \cdot{ }^{23,39,41}$ The diffraction pattern can be fully explained with a turbostratic disorder and concomitant interstratification of domains with grafted carbonate and domains with intercalated carbonate. In any case, side phases are not indicated in the diffraction pattern. This is in contrast with previous reports, where GR was oxidized in an ambient atmosphere or by bubbling oxygen through the suspension where mixtures of $\mathrm{GR}^{*}$ with goethite are obtained instead of phase pure $\mathrm{GR}^{*} \cdot{ }^{27,42}$ Both the strategies presented herein, however, yield the desired product with no side phases. The first reflex of $\mathrm{GR}^{*}$ appears at $7.1 \AA\left(\mathrm{GR}^{*}{ }_{\mathrm{ChOx}}\right)$ and $7.3 \AA$ $\left(\mathrm{GR}^{*}{ }_{\text {ElOx }}\right)$ and has been related to the basal spacing. ${ }^{41}$ However, an integral $00 l$ series is missing, indicating heavy random interstratification. The apparent basal spacing of both samples is lower as compared to that of the mixed-valence parent GR $(7.5 \AA) .{ }^{40}$ In $\mathrm{GR}^{*}{ }_{\text {ElOx }}$, the (001) reflection is rather sharp and more intense as compared to that in $\mathrm{GR}^{*}{ }_{\mathrm{ChOx}}$. Moreover, even the (002) reflection $(d=3.7 \AA)$ is visible while being submerged into the background when the oxidation is performed chemically.

We have previously shown that the oxidation of mixedvalence Fe-LDHs triggers partial grafting (i.e., chemical bonding) of interlayer carbonate to the brucite-like layers. ${ }^{39}$ Density functional theory (DFT) calculations have shown that the completely grafted structure shows a basal spacing, which is $0.3 \AA$ smaller than that for the non-grafted $\mathrm{LDH}^{39}$ A similar trend was found in CoFe-LDHs, where it was found that a higher Fe-content promoted more grafting. ${ }^{43}$ In the presence of $\mathrm{H}_{2} \mathrm{O}_{2}$, the grafting was shown by DFT to proceed exothermically, which constitutes the driving force for the grafting process. ${ }^{39}$ Grafting can also be qualitatively supported by FT-IR, as discussed below. Thus, the variations in the apparent basal spacings found for $\mathrm{GR}^{*}{ }_{\mathrm{ChOx}}$ and $\mathrm{GR}^{*}{ }_{\text {ElOx }}$ are attributed to a random interstratification of grafted and intercalated domains. The higher intensity and higher $d$-value observed for $\mathrm{GR}^{*}{ }_{\text {ElOx }}$ indicate significantly fewer grafted domains being produced by electrochemical oxidation as compared to chemical oxidation $\left(\mathrm{GR}^{*}{ }_{\mathrm{ChOx}}\right)$. Employing electrooxidation (i.e., in the absence of $\mathrm{H}_{2} \mathrm{O}_{2}$ ), the driving force for grafting might be smaller as compared to chemical oxidation and consequently, more intercalated (i.e. ungrafted) domains contribute to random interstratification leading to an overall higher observed basal spacing of $7.3 \AA$.

To corroborate the varying grafting probability with the oxidation method, FT-IR spectra were recorded (Fig. 3). Based on the symmetry of the carbonate ion, it is possible to experimentally distinguish between non-grafted interlayer carbonate and carbonate ions that are grafted to the brucite layers. The former features a $D_{3 \mathrm{~h}}$ symmetry, whereas the latter shows symmetry reduction to $C_{2 \mathrm{v}}$. As shown in the previous work, the $\nu_{3}$ vibration band of $\mathrm{CO}_{3}{ }^{2-}$ at $1350 \mathrm{~cm}^{-1}$ may be used to quantify grafting. Symmetry reduction due to grafting manifests as an energetic splitting of this band to a second one observable at $1485 \mathrm{~cm}^{-1}$, which is characteristic of the grafted carbonate species. ${ }^{39}$ Irrespective of the oxidation method, these two bands are present. The relative intensity of these two bands furthermore allows for the assessment of the extent of grafted and non-grafted species qualitatively. Both bands, assigned to grafted and ungrafted carbonate species, exhibit roughly similar intensity for $\mathrm{GR}^{*}{ }_{\mathrm{ChOx}}$. For $\mathrm{GR}^{*}{ }_{\text {ElOx }}$, however, the band's relative intensity at $1485 \mathrm{~cm}^{-1}$ is notably decreased. Thus, it can be concluded that grafting of carbonate species is less prevalent when performing electro-oxidation. This phenomenon is in line with the above interpretation of the XRD patterns (Fig. 2b). It suggests that oxidation with a potent

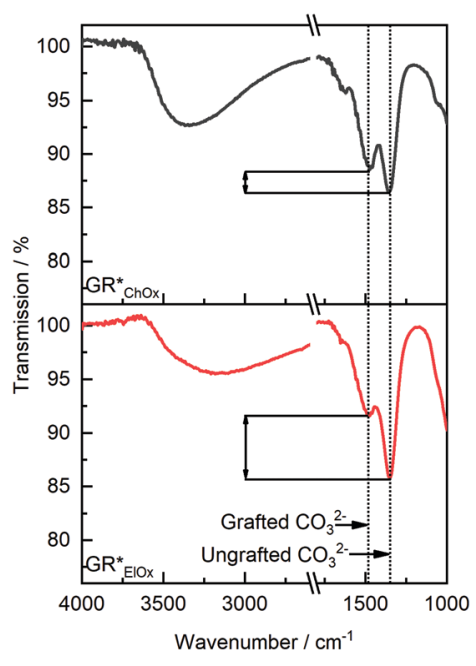

Fig. 3 Normalized FT-IR spectra of $\mathrm{GR}^{*}{ }_{\mathrm{ChOx}}$ (gray) and $\mathrm{GR}^{\star}{ }_{\mathrm{ElOx}}$ (red). Carbonate peak splitting is found in both samples. Based on the relative intensity of grafted and ungrafted carbonate peaks, a lower proportion of grafted $\mathrm{CO}_{3}{ }^{2-}$ can be obtained for $\mathrm{GR}^{\star}{ }_{\text {ElOx }}$. 
chemical oxidation agent, such as $\mathrm{H}_{2} \mathrm{O}_{2}$, provides a stronger driving force for grafting as compared to electro-oxidation.

Besides basal reflections, only asymmetric, non-uniformly broadened reflections are observed in the diffraction patterns of both $\mathrm{GR}^{*}$ samples. As previously shown, ${ }^{39}$ they originate from two-dimensional diffraction by the brucite layers being stacked with the random phase (turbostratic disorder) leading to $h k$-bands.

The SEM images of both GR* samples (Fig. S3a-d, ESI confirm the coating on the substrate. The micrographs of the bare steel substrate merely show some surface roughness due to polishing (Fig. S3e and f, ESI ). For both chemically and electrochemically oxidized samples, the deposited layer features a plate-like morphology typically observed for LDHs. The steel substrate is completely coated and the coating appears to be uniform. The platy crystals of both $\mathrm{GR}^{*}$ samples feature dimensions ranging from $0.4 \mu \mathrm{m}$ to $4.5 \mu \mathrm{m}$ in diameter and $40-80 \mathrm{~nm}$ in thickness. Large platelets are found to be intergrown, with smaller platelets providing an increased number of edges and corner sites, contributing to the OER activity. ${ }^{22}$ A similar appearance of both samples indicates the topotactic transformation of GR to $\mathrm{GR}^{*}$ and thus the morphology is determined already in the first step, the electrochemical deposition of GR, with little to no morphology change occurring upon the formation of $\mathrm{GR}^{*}{ }^{44}$ This conclusion is supported by the SEM micrographs of GR acquired prior to oxidation (Fig. S4, ESI $\ddagger$ ).

The Mössbauer spectra of chemically and electrochemically oxidized samples are also very similar (Fig. S5, ESI ). The ${ }^{57} \mathrm{Fe}$ spectra were acquired at room temperature consisting of a single, broad doublet with a mean quadrupole splitting of $0.67 \mathrm{~mm} \mathrm{~s}^{-1}$ and $0.75 \mathrm{~mm} \mathrm{~s}^{-1}$ and an isomer shift of $0.35 \mathrm{~mm} \mathrm{~s}^{-1}$ and $0.36 \mathrm{~mm} \mathrm{~s}^{-1}$ with respect to metallic iron. These values agree well with those expected for $\mathrm{GR}^{*} .^{40,41}$ Complete oxidation from $\mathrm{Fe}^{2+}$ to $\mathrm{Fe}^{3+}$ can be achieved for both samples as no residual ferrous doublet can be observed in the acquired spectra. Not surprisingly, Mössbauer spectroscopy is insensitive to the degree of grafting.

Both $\mathrm{GR}^{*}$ samples were tested for OER catalysis. The electrochemically active surface area (ECSA) is calculated (Fig. 4a) by performing $\mathrm{CV}$ in a non-faradaic regime at different scan rates (Fig. S6, ESI $\$$ ). Due to the influence of the setup and the method of determining the absolute ECSA, ${ }^{12}$ we only use the ECSA as an activity parameter to compare the samples obtained within this study. For this purpose, the relative ECSA of the untreated steel plate is compared with those of $\mathrm{GR}^{*} \mathrm{ChOx}$ and $\mathrm{GR}^{*}$ ElOx .

Compared to a non-coated sample, the controlled corrosion producing GR and then GR* leads to an approximately 2.4- and 2.7-fold increase in the ECSA for $\mathrm{GR}^{*}{ }_{\mathrm{ChOx}}$ and $\mathrm{GR}^{*}{ }_{\mathrm{ElOx}}$, respectively. Regarding the different oxidation methods, $\mathrm{GR}^{*}$ ElOx has a slightly higher relative ECSA.

LSV experiments are performed and compared to the overpotential $(\eta)$ of the uncoated substrate (Fig. 4b). Comparing the two $\mathrm{GR}^{*}$ samples with varying degrees of grafting furthermore will allow for the first-time conclusion regarding the effect of grafting on the OER performance.
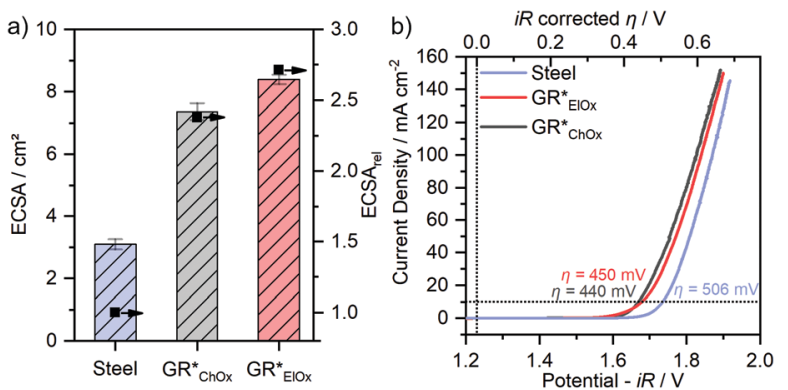

Fig. 4 (a) Electrochemically active surface area with normalized relative ECSA and (b) linear sweep voltammograms for all three samples: the pristine steel plate, $\mathrm{GR}^{*}{ }_{\mathrm{ElOx}}$, and $\mathrm{GR}^{*}{ }_{\mathrm{ChOx}}$. LSVs were recorded with a scan rate of $5 \mathrm{mV} \mathrm{s}^{-1}$ in $\mathrm{O}_{2}$-saturated purified $1 \mathrm{M} \mathrm{KOH}$ solutions.

$\mathrm{GR}^{*}$ ChOx and $\mathrm{GR}^{*}$ Elox showed overpotentials of $\eta=440 \mathrm{mV}$ and $\eta=450 \mathrm{mV}$, respectively, at a current density of $10 \mathrm{~mA} \mathrm{~cm}^{-2}$ while for the uncoated bare steel plate, $\eta=506 \mathrm{mV}$ is necessary. A current density of $100 \mathrm{~mA} \mathrm{~cm}{ }^{-2}$ was reached at the overpotentials of $598 \mathrm{mV}$ for $\mathrm{GR}^{*}{ }_{\mathrm{ChOx}}$ and $610 \mathrm{mV}$ for $\mathrm{GR}^{*}{ }_{\text {ElOx }}$. The absence of any notable pre-peaks is consistent with the expectations and conclusions from the Mössbauer spectroscopy measurements, as both electrocatalysts have been fully oxidized to the all-ferric oxidation state.

Compared to the uncoated steel plate, both $\mathrm{GR}^{*}$ catalyst materials show a clear OER activity improvement. The overpotentials at $10 \mathrm{~mA} \mathrm{~cm} \mathrm{~cm}^{-2}$ are in the range reported for mössbauerite synthesized at room temperature $(\eta=540 \mathrm{mV})$ and at a temperature of $50{ }^{\circ} \mathrm{C}(\eta=400 \mathrm{mV})$. The offset may be attributed to the different synthesis methods and the rotating disc electrode setup being used to determine the latter values.

Despite the slightly higher ECSA of $\mathrm{GR}^{*}{ }_{\text {ElOx }}$ compared to $\mathrm{GR}^{*}{ }_{\mathrm{ChOx}}$, the latter exhibits a higher activity over the probed potential range. Normalization of the polarization curves to the ECSA (Fig. S7, ESI $\$$ ) further confirms the higher intrinsic activity of $\mathrm{GR}^{*}{ }_{\mathrm{ChOx}}$ compared to $\mathrm{GR}^{*}{ }_{\mathrm{ElOx}}$. We attribute this to the higher degree of carbonate grafting of $\mathrm{GR}^{*}{ }_{\mathrm{ChOx}}$ which can be regarded as a formal replacement of $\mathrm{OH}^{-}$with $\mathrm{CO}_{3}{ }^{2-}$, modulating the electronic structure and thus the redox activity of the metal center. According to the HSAB principle, the softer base $\mathrm{OH}^{-}$donates electron density to the adjacent metal centers more readily than the harder base $\mathrm{CO}_{3}{ }^{2-} \cdot{ }^{45}$ Therefore, a lower electron density is expected at the electrocatalytically active transition-metal center for $\mathrm{GR}^{*}{ }_{\mathrm{ChOx}}$ as compared to $\mathrm{GR}^{*}$ ElOx. Investigations on NiFe-LDHs have shown that such reduced electron density, charge delocalization and the incorporation of electron-withdrawing anions or cations can be beneficial for the facilitation of higher-valent electrophilic transition metal ion sites. At these sites, the nucleophilic attack of hydroxyl and water molecules is promoted, leading to improved adsorption of reaction intermediates during the OER. ${ }^{46,47}$

In order to investigate the stability and versatility of the catalyst during continuous operation, chronopotentiometry experiments were conducted. Here, the galvanostatic performance was investigated by applying a current corresponding to a current density of $10 \mathrm{~mA} \mathrm{~cm} \mathrm{~cm}^{-2}$ for $24 \mathrm{~h}$ in $1 \mathrm{M} \mathrm{KOH} \mathrm{(Fig.} \mathrm{S8,}$ 
ESI ). Over this time, the necessary overpotential to maintain this current was recorded. Initially, $\mathrm{GR}^{*}{ }_{\mathrm{ElOx}}$ and $\mathrm{GR}^{*}{ }_{\mathrm{ChOx}}$ allow achieving the current density of $10 \mathrm{~mA} \mathrm{~cm}^{-2}$ at lower potentials than the uncoated substrate. Throughout the experiment, an increase of the potential was recorded for $\mathrm{GR}^{*}$ ElOx $(+21 \mathrm{mV}), \mathrm{GR}^{*}$ ChOx $(+30 \mathrm{mV})$, and the uncoated bare steel substrate $(+26 \mathrm{mV})$.

The decrease in the performance of both $\mathrm{GR}^{*}$ samples may be related to various effects such as the physical detachment of the catalyst material under operating conditions or degradation resulting in the loss of activity and active sites. ${ }^{23}$ Interestingly, the potential of $\mathrm{GR}^{*}{ }_{\mathrm{ChOx}}$ increased the most during the first 2 hours of the experiment (inset Fig. S8, ESI $\$$ ). Most likely, this is caused by the energy released during harsh chemical oxidation, which might result in a less intimate contact between the substrate and the catalyst. Thus, $\mathrm{GR}^{*}{ }_{\mathrm{ChOx}}$ is more prone to a loss of electrical contact during operation. Due to the prior electrochemical treatment, GR* ${ }_{\text {ElOx }}$ shows an initial performance increase which could be related to the easier formation of percolation paths and active sites. In $\mathrm{GR}^{*}{ }_{\mathrm{ChOx}}$, these improving changes are delayed and masked by possible detrimental alterations discussed earlier.

As expected, the performance of the uncoated steel also decreases, likely due to the formation of inactive corrosion products blocking the access to more electroactive centres. The formation of such products was also evidenced by the brownish-black staining of the surface after the experiment.

To gain insight into the alteration of catalysts during catalysis, post-catalysis SEM studies of the employed electrodes were performed. For the bare steel substrate, the results evidence the formation of a porous surface layer (Fig. S9a and b, ESI $\$$ ). This indicates the oxidation of $\mathrm{Fe}^{0}$ to soluble Fe-species as predicted by the Pourbaix diagram discussed earlier. Alteration of the electrode under the current load was also evident by the previously described brown-black staining. The post-catalysis XRD measurements (Fig. S10, ESI $\ddagger$ ) indicate the presence of $\mathrm{Fe}_{1-x} \mathrm{O}$ and $\mathrm{Fe}_{3} \mathrm{O}_{4}$ deposits formed via reprecipitation. Presumably, these deposits are responsible for the deterioration of catalytic performance during the chronopotentiometry measurements.

For $\mathrm{GR}^{*}{ }_{\mathrm{ChOx}}$ and $\mathrm{GR}^{*}{ }_{\text {ElOx }}$ catalysts, the platelet-like morphology was generally preserved, although a loss of the catalyst material $(-23 \%$, determined gravimetrically) was observed during the stability experiment. The SEM analysis moreover indicates the degradation of the hexagonal platelet shapes to more rounded corners and the secondary deposits covering the platelets after $24 \mathrm{~h}$ (Fig. S9c-f, ESI $\$$ ). Based on our previous study examining the stability of mössbauerite in a setup using a rotating disc electrode, we conclude that during electrolysis, small amounts of the catalyst can be dissolved into the electrolyte and are redeposited as amorphous iron (oxy)hydroxides. ${ }^{23}$ The post-catalysis XRD measurements (Fig. S10, ESI $\$$ ) do not show any crystalline phase other than $\mathrm{GR}^{*}$ and steel.

\section{Conclusions}

Manufacturing catalyst-coated electrodes through a controlled, cheap, and time-efficient corrosion engineering process of steel presents a viable way to obtain electrodes for the oxygen evolution reaction. A carbon steel substrate was used to deposit the known iron-only electrocatalyst $\mathrm{GR}^{*}$ via its precursor GR. Clearly, the choice of oxidation method, i.e., chemical or electrochemical oxidation, has a notable influence on the structural constitution and performance of the catalyst. Chemical oxidation gives a higher degree of grafting, which appears to be advantageous for the catalytic performance.

Based on these results, further developments will aim towards maximizing the catalyst's coverable surface area, e.g., by deposition on steel wool or iron foam. Of course, concomitant doping can further improve the performance as well.

\section{Author contributions}

Sebastian Weiß: investigation, formal analysis, writing - original draft, and writing - review \& editing; A. V. Radha: investigation; Catherine McCammon: investigation, formal analysis, and resources; Michael Ertl: investigation; Josef Breu: resources, supervision, writing - original draft, and writing - review \& editing.

\section{Conflicts of interest}

There are no conflicts of interest to declare.

\section{Acknowledgements}

The authors are grateful for financial support from the Deutsche Forschungsgemeinschaft (DFG) within the collaborative research center 840 "From particulate nanosystems to mesotechnology" (79971943; SFB 840). They thank Mirijam Zobel for the measurement time with her powder X-ray diffractometer. The authors thank $\mathrm{O}$. Khoruzhenko for the graphic design. They further thank R. Timmins and C. Habel for their advice and proofreading the manuscript. They appreciate the support from the Keylab for Optical and Electron Microscopy of the Bavarian Polymer Institute (BPI). They thank Marco Schwarzmann for the corresponding measurements. S. W. acknowledges the support from the Elite Network of Bavaria and thanks the graduate school of the Bavarian Center for Battery Technology (BayBatt) for ongoing support.

\section{Notes and references}

1 Z. W. Seh, J. Kibsgaard, C. F. Dickens, I. Chorkendorff, J. K. Nørskov and T. F. Jaramillo, Science, 2017, 355, eaad4998.

2 S. Chu and A. Majumdar, Nature, 2012, 488, 294-303.

3 J. Yin, A. Molini and A. Porporato, Nat. Commun., 2020, 11, 4781.

4 D. Zhao, Y. Pi, Q. Shao, Y. Feng, Y. Zhang and X. Huang, ACS Nano, 2018, 12, 6245-6251.

5 I. Roger, M. A. Shipman and M. D. Symes, Nat. Rev. Chem., 2017, 1, 0003. 
6 L. Wu, L. Yu, X. Xiao, F. Zhang, S. Song, S. Chen and Z. Ren, Research, 2020, 2020, 17.

7 R. Tolouei, J. Harrison, C. Paternoster, S. Turgeon, P. Chevallier and D. Mantovani, Phys. Chem. Chem. Phys., 2016, 18, 19637-19646.

8 D. G. Lee and H. Gai, Can. J. Chem., 1993, 71, 1394-1400.

9 J. M. Schreyer and L. T. Ockerman, Anal. Chem., 1951, 23, 1312-1314.

10 R. M. Cornell and U. Schwertmann, The Iron Oxides: Structure, Properties, Reactions, Occurrences and Uses, Wiley, 2006.

11 S. Papavinasam, in Corrosion Control in the Oil and Gas Industry, ed. S. Papavinasam, Gulf Professional Publishing, Boston, 2014, pp. 133-177.

12 S. Anantharaj, S. R. Ede, K. Karthick, S. Sam Sankar, K. Sangeetha, P. E. Karthik and S. Kundu, Energy Environ. Sci., 2018, 11, 744-771.

13 H. Zhong, J. Wang, F. Meng and X. Zhang, Angew. Chem., Int. Ed., 2016, 55, 9937-9941.

14 B. A. Marinho, R. O. Cristóvão, R. A. R. Boaventura and V. J. P. Vilar, Environ. Sci. Pollut. Res., 2019, 26, 2203-2227.

15 F. Guo, Y. Wu, H. Chen, Y. Liu, L. Yang, X. Ai and X. Zou, Energy Environ. Sci., 2019, 12, 684-692.

16 X. Liu, B. You and Y. Sun, ACS Sustainable Chem. Eng., 2017, 5, 4778-4784.

17 H. Schäfer, S. Sadaf, L. Walder, K. Kuepper, S. Dinklage, J. Wollschläger, L. Schneider, M. Steinhart, J. Hardege and D. Daum, Energy Environ. Sci., 2015, 8, 2685-2697.

18 H. Sun, J. Brocato and M. Costa, Curr. Environ. Health Rep., 2015, 2, 295-303.

19 S. Mitra, A. Sarkar and S. Sen, Nanotechnol. Environ. Eng., 2017, 2, 11.

20 Y. Liu, X. Liang, L. Gu, Y. Zhang, G.-D. Li, X. Zou and J.-S. Chen, Nat. Commun., 2018, 9, 2609.

21 H. Schäfer, S. M. Beladi-Mousavi, L. Walder, J. Wollschläger, O. Kuschel, S. Ichilmann, S. Sadaf, M. Steinhart, K. Küpper and L. Schneider, ACS Catal., 2015, 5, 2671-2680.

22 Y. Wang, D. Yan, S. El Hankari, Y. Zou and S. Wang, Adv. Sci., 2018, 5, 1800064.

23 M. Ertl, C. Andronescu, J. Moir, M. Zobel, F. E. Wagner, S. Barwe, G. Ozin, W. Schuhmann and J. Breu, Chem. - Eur. J., 2018, 24, 9004-9008.

24 M. Usman, J. M. Byrne, A. Chaudhary, S. Orsetti, K. Hanna, C. Ruby, A. Kappler and S. B. Haderlein, Chem. Rev., 2018, 118, 3251-3304.

25 U. Schwertmann and H. Fechter, Clay Miner., 1994, 29, 87-92.

26 M. Abdelmoula, P. Refait, S. H. Drissi, J. P. Mihe and J. M. R. Génin, Corros. Sci., 1996, 38, 623-633.
27 L. Legrand, L. Mazerolles and A. Chaussé, Geochim. Cosmochim. Acta, 2004, 68, 3497-3507.

28 G. J. Long, T. Cranshaw and G. Longworth, Moessbauer Eff. Ref. Data J., 1983, 6, 42-49.

29 C. McCammon, V. Chaskar and G. Richards, Meas. Sci. Technol., 1991, 2, 657.

30 C. A. McCammon, Hyperfine Interact., 1994, 92, 1235-1239.

31 C. Prescher, C. McCammon and L. Dubrovinsky, J. Appl. Crystallogr., 2012, 45, 329-331.

32 Bio-Rad Laboratories, Chelex(R) 100 and Chelex 20 Chelating Ion Exchange Resin - Instruction Manual, https://www. bio-rad.com/webroot/web/pdf/lsr/literature/LIT200.pdf, 2021.

33 H. Deng, C. Zhang, Y. Xie, T. Tumlin, L. Giri, S. P. Karna and J. Lin, J. Mater. Chem. A, 2016, 4, 6824-6830.

34 C. C. L. McCrory, S. Jung, J. C. Peters and T. F. Jaramillo, J. Am. Chem. Soc., 2013, 135, 16977-16987.

35 P. Refait and J.-M. Génin, Corros. Sci., 1993, 34, 797-819.

36 G. Ona-Nguema, M. Abdelmoula, F. Jorand, O. Benali, A. Géhin, J. C. Block and J. M. R. Génin, Hyperfine Interact., 2002, 139, 231-237.

37 L. Legrand, S. Savoye, A. Chausse and R. Messina, Electrochim. Acta, 2000, 46, 111-117.

38 J.-M. R. Génin, C. Ruby, A. Géhin and P. Refait, C. R. Geosci., 2006, 338, 433-446.

39 P. Lyu, M. Ertl, C. J. Heard, L. Grajciar, A. V. Radha, T. Martin, J. Breu and P. Nachtigall, J. Phys. Chem. C, 2019, 123, 25157-25165.

40 J. M. R. Génin, A. Christy, E. Kuzmann, S. Mills and C. Ruby, Hyperfine Interact., 2014, 226, 459-482.

41 J. M. R. Génin, S. J. Mills, A. G. Christy, O. Guérin, A. J. Herbillon, E. Kuzmann, G. Ona-Nguema, C. Ruby and C. Upadhyay, Mineral. Mag., 2014, 78, 447-465.

42 C. Ruby, M. Abdelmoula, S. Naille, A. Renard, V. Khare, G. Ona-Nguema, G. Morin and J.-M. R. Génin, Geochim. Cosmochim. Acta, 2010, 74, 953-966.

43 S. Weiß, M. Ertl, S. D. Varhade, A. V. Radha, W. Schuhmann, J. Breu and C. Andronescu, Electrochim. Acta, 2020, 350, 136256.

44 J.-M. R. Génin, C. Ruby and C. Upadhyay, Solid State Sci., 2006, 8, 1330-1343.

$45 \mathrm{H} . \mathrm{Xu}$, D. C. $\mathrm{Xu}$ and Y. Wang, ACS Omega, 2017, 2, 7185-7193.

46 L. Fan, P. Zhang, B. Zhang, Q. Daniel, B. J. J. Timmer, F. Zhang and L. Sun, ACS Energy Lett., 2018, 3, 2865-2874.

47 Y.-Y. Dong, D.-D. Ma, X.-T. Wu and Q.-L. Zhu, Inorg. Chem. Front., 2020, 7, 270-276. 